DOI 10.37882/2500-3682.2020.12.03

\title{
СТРУКТУРА ПРОФЕССИОНАЛЬНО ЗНАЧИМЫХ КАЧЕСТВ ИНЖЕНЕРА КАК ОСНОВА НАДЕЖНОСТИ ТРУДА
}

\section{STRUCTURE OF PROFESSIONAL QUALITIES OF AN ENGINEER AS THE BASIS OF RELIABILITY OF WORK \\ Ye. Balakshina}

Summary: Modernization of modern industrial complexes and active development of enterprises in various areas of the labor market leads to an increase in the prestige of engineering professions. Numerous innovations introduced in the technological process to ensure its reliability and increase efficiency contribute to the formation of new specialties in engineering. These trends provide an opportunity: for the employment of young professionals with technical education in its more prestigious areas; to realize creative potential in work activity; to advance on the career "ladder.» It should be noted that the most preferred and desirable professional fields of engineering in choosing it as a matter of «life,» from an economic point of view, are information technology, biotechnology, nanotechnology, construction. In this regard, the high significance of the discoveries of engineering thought, its results for the life of society constantly raises questions about the training of high-class engineers confirming their level in practice. The possibility of taking into account psychological trends in the process of professional development of an engineer by differentiating leading professionally significant qualities and highlighting the structure of qualities of an engineer becomes an important basis, which in the future will contribute to the implementation of labor functions at a reliable and safe level already at the stage of entering the profession.

Keywords: engineer, engineering activity, efficiency of activity, creativity, reliability, professionally significant qualities, ability, technical solutions.

\section{Введение}

$\Pi$ роблема детализации психологического содержания профессиональной деятельности на примере технических профессий не теряет своей актуальности в рамках психологии труда и инженерной психологии. Данное обстоятельство во многом связано с интенсивной технологизацией и компьютеризацией различных видов труда, что значительно усложняет его реализацию, обусловленную включением дополнительных функций, расширением обязанностей, усложнением задач, решаемых специалистом. При этом ориентация на запланированный результат труда во многом зависит от способности профессионала не просто применять специальные знания конкретной профессиональной предметной области, но и интегрировать их со знаниями
Балакшина Елена Владимировна

К.nсх.н., дочент, Тверской государственный технический университет balakshina79@mail.ru

Аннотация: Модернизация современных промышленных комплексов и активное развитие предприятий в различных сферах рынка труда приводит к росту престижа инженерных профессий. Многочисленные инновации, внедряемые в технологический процесс для обеспечения его надежности и роста эффективности, способствуют образованию новых специальностей в инженерном деле. Данные тенденции дают возможность: для трудоустройства молодых профессионалов с техническим образованием в более престижных его направлениях; для реализации творческого потенциала в трудовой деятельности; для продвижения по карьерной «лестнице». Следует отметить, что наиболее предпочтительными и желаемыми профессиональными сферами инженерного профиля при выборе его как дела «жизни», с экономической точки зрения, являются информационные технологии, биотехнологии, нанотехнологии, строительство. В связи с этим, высокая значимость открытий инженерной мысли, ее результатов для жизни социума постоянно поднимает вопросы о подготовке инженеров высокого класса, подтверждающих свой уровень на практике. Возможность учета психологических тенденций в процессе профессионального становления инженера посредством дифференциации ведущих профессионально значимых качеств и выделения структуры качеств инженера становится важной основой, которая в дальнейшем будет способствовать реализации трудовых функций на надежном и безопасном уровнях уже на этапе вхождения в профессию.

Ключевые слова: инженер, инженерная деятельность, креативность, надежность, профессионально значимые качества, способность, технические решения, эффективность деятельности.

смежных областей.

Применительно к инженерному делу продукт деятельности представляет собой проект, конструкт, макет и др. и обусловлен спецификой сферы промышленности, в которой функционирует предприятие, где ведущим ориентиром в условиях современной экономики является нацеленность на рынок и потребителя. В данных условиях работодатель настроен на коммерческий успех и ожидает от инженера не просто обычного исполнения своих обязанностей, а выпуска «нечто нового», неординарного. Скорость внедрения инноваций в жизнь, ее различные стороны, их постоянная смена также являются важными факторами, оказывающими влияние на формирование ряда требований относительно наличия соответствующих профессиональных компетенций ин- 
женера. Таким образом, способность сотрудников инженерно-технической службы разрабатывать и иннервировать нестандартные решения становится ключевым моментом для успеха организации.

Делая акцент на способности творить и принимать нестандартные решения, как важном условии успешности инженерного труда, нельзя исключать из внимания, что реальная возможность исполнять «чисто» инженерные виды деятельности на практике становится доступной на базе профильных организаций. Тенденция непрерывного оснащения современными техническими средствами иные сферы труда (медицина, образование и другие социальные сферы) привела к росту потребности в инженерных кадрах. Профессиональная деятельность инженера, задействованного в организациях непрофильного типа, в большей степени отличается предметно-практической, социальной направленностью, зачастую без возникающих трудных повседневных вопросов, для решения которых необходимо применение инженерноинновационных и научно-исследовательских разработок [4]. В данном случае даже при наличии классического инженерного образования качественное и надежное выполнение трудовых задач достигается наличием профессиональных компетенций, обобщенного паттерна профессионально важных качеств, характерного для представителей технических профессий, а способность к креативности уходит на второй план. Дополнительным фактором, обуславливающим необходимость изучения различных сторон профессиональной инженерной деятельности, также выступает такое явление, как размытость ее границ. Заложенные должностные обязанности специалистов ряда инженерных направлений имеют на функциональном уровне разительные отличия от общепринятого понимания содержания инженерной деятельности (инженер-экономист, инженер-снабженец и др.) и приводят к многозадачности ее реализации.

\section{Теоретическая основа исследования}

Опираясь на системогенетический подход, необходимо отметить, что интенсивное внедрение результатов технического прогресса в социально-экономическую сферу выступает в качестве одного из основных условий, дифференцирующих показатели надежности, успешности и эффективности деятельности инженера на современном рынке труда [8, с. 111]. Нередко выступая в качестве модератора всего технологического процесса на предприятии, инженер решает дополнительные проблемы, связанные с управлением, обеспечением контроля и организацией работы технических отделов, а также несет дополнительную ответственность за принимаемые решения. В этом смысле построение и осмысление теоретической модели, в которой будет отражена структура и набор эталонных профессионально значимых качеств на основе изучения специфики психологического содержания деятельности инженера разной профессиональной направленности, с учетом стадии (этапа) профессионального становления, становится актуальной в психологии труда и инженерной психологии.

Обоснование и выделение эталона, который будет описывать набор ведущих профессионально важных качеств, возможно посредством анализа ожидаемых, формируемых умений современного инженера. Исходя из приведенных выше особенностей инженерной деятельности, традиционно от инженера как технического специалиста ожидают работы над технической документацией, надзора за изготовлением авторской продукции, налаживания каналов коммуникации с заказчиками и пользователями проектов [4, с. 2]. При этом высокие требования к его умениям, навыкам и знаниям, представленные в многочисленных профессиограммах, их широкий спектр не всегда реализуется в деятельности. На практике специалист инженерной деятельности смежного характера может выполнять ряд конкретных функций и задач на протяжении длительного времени [6]. Поэтому структура профессионально значимых качеств специалистов даже внутри одной профессии может значительно отличаться [7].

Проблема формирования профессионально значимых качеств широко представлена в трудах отечественных психологов в рамках психологии труда (А.В. Батаршев, А.Н. Воронин, А.А. Деркач, Е.П. Ермолаева, В.В. Козлов, В.А. Толочек, В.Д. Шадриков и др.) [2]. Получение совокупности данных, сведений и образов о специфике содержания структуры профессионально важных качеств применительно к конкретному виду труда возможно на основе применения деятельностного, личностного, компетентностного, системного и интегративного подходов [3]. Относительно инженерных специальностей в приоритете остаются вопросы, связанные с необходимостью поиска адекватных критериев продуктивности, производительности деятельности с учетом, что не все существующие виды в конечном итоге направлены на создание продукта, или сам продукт труда может быть весьма специфичен [9]. ценка взаимосвязи качества, результативности и надежности деятельности инженера с профессионально важными качествами требует особого внимания и детального рассмотрения. Обобщающим фактором является то, что успешность выполнения трудовых функций поддерживается развитыми в процессе профессионализации профессионально важными качествами [11]. 


\section{Методы исследования}

Одним из основных методов, применяемых для изучения особенностей трудовой деятельности, является профессиографический. При комплексном подходе к изучению конкретного вида деятельности данный метод выступает в качестве фундамента и первичного этапа для процесса всестороннего анализа и систематизации выявленных характерных закономерностей труда. Пристальное внимание к средствам, условиям, функциональным обязанностям и историческому генезису профессии позволяет провести дифференциацию ее содержательных и структурных показателей.

Системогенетический метод исследования позволяет определить профессионально важные качества как комплекс любых качеств субъекта, непосредственно включенный в процесс деятельности и обеспечивающий эффективность ее реализации по показателям производительности и надежности (А. Батаршев, И. Алексеева, Е. Майорова) [3]. Паттерн профессионально важных качеств обусловлен особенностями выполняемой деятельности. В.Д. Шадриковым предложено следующее определение профессионально важных качеств - это особый паттерн индивидуальных качеств субъекта труда, оказывающий влияние на эффективность деятельности, а также на процесс успешности ее освоения. Автором отмечается динамичность некоторых профессионально важных качеств, основанных на чертах личности и психомоторных свойствах [9].

Состав профессионально важных качеств представлен рядом физических, антропометрических, физиологических характеристик человека, определяющих успешность человека в учебной и трудовой деятельности. Формирование перечня указанных качеств должно проводиться с учетом специфики состава, степени выраженности тех или иных качеств, установлению связей внутри выделенной структуры. Весь анализ проводится на базисе профессиограммы с последующим составлением психограммы [10].

\section{Результаты исследования}

Инженер как специалист, осуществляющий инженерную деятельность, согласно научным источникам должен обладать способностью к изобретению [6].

Согласно В.П. Алексееву, наличие творческого начала у инженера проявляется в быстроте принимаемых решений, степени их разумности и взвешенности [1, с. 6]. Автором также анализируется скорость синтезирования новых технических решений и способности укладывать- ся в уставленные сроки со смышленностью. В более современном понимании инженер - это специалист, который обладает знаниями в области техники и технологий, экономики, производства, человеческих отношений, способный самостоятельно пользоваться инженерными методами [5]. Спектр знаний, необходимый для эффективности труда, включает высокий уровень выраженности теоретических, научных, технических изысканий, а также навыки по черчению. В наиболее классических вариантах инженерного дела профессиональная область больше ориентирована на технику.

Анализ профессиограммы инженера позволил выделить доминирующие виды деятельности (отчетная, планирование, разработка, сбор информации, опытные работы, проектирование, описание, настройка, испытание, внедрение, научно-исследовательская, конструирование), а также ключевые признаки профессии инженера [6]. Такая мультипредставленность требует наличия широкого набора способностей: от математических до особенностей познавательной сферы (внимание, память, мышление, воображение). Надежный и эффективный уровень исполнения профессиональных требований достигается также спецификой личностных качеств, интересов и склонностей. Основной ярус наиболее значимых качеств составляют: усидчивость, аккуратность, рациональность, пунктуальность, терпеливость, скрупулезность, любознательность, методичность [10]. Именно они позволяют инженеру успешно реализоваться в профессии на предприятиях любого профиля.

\section{Зак^ючение}

Таким образом, современная инженерная деятельность обладает рядом специфических особенностей. Ведущими ее чертами, как и в других видах труда, являются информационное и технологическое насыщение производственного процесса. В данных условиях эффективность, надежность и успешность инженерного труда зависит от способности быстро адаптироваться к новым реалиям, проявляя творческую активность и креативность. Своеобразие паттерна профессионально значимых качеств инженера обусловлено длительным процессом становления с последовательным наращиванием ведущих и редукцией малозначимых качеств. Как показывает практика, на сегодняшний день актуальным направлением инженерной психологии и психологии труда становится оценка надежности инженерной деятельности и ее продуктивности в целом. Поэтому решение задач, направленных на раскрытие структуры профессионально важных качеств и особенностей психологического содержания инженерной деятельности с учетом стадий профессионального развития, заслуживает продолжения углубленного исследования. 


\section{ЛИТЕРАТУРА}

1. Алексеев В.П. Категория творчества в профессиональной инженерной деятельности // Научно-практический журнал «Новые исследования в разработке техники и технологий. 2015. №2. С. 5-12.

2. Барткевич Е.В., Бадалян Ю.В., Зенина С.Р. Исследование психологических детерминант индивидуального стиля деятельности сотрудников телекоммуникационной компании // Современная наука: актуальные проблемы теории и практики. Серия «Познание». -2018. -№5. -С. 67-72.

3. Батаршев А.В., Алексеева И., Майорова Е. Диагностика профессионально важных качеств. СПб.: Питер, 2007. 192 с.

4. Гаранина 0.Д. Инженерная деятельность в контексте социально ответственности // Международный научно-исследовательский журнал. 2016. №4-4 (46). C.2-4.

5. Гинзбург Д.А. Актуальность психологии в различных сферах профессиональной деятельности современного человека // Современная наука: актуальные проблемы теории и практики. Серия «Познание». -2019. -№5. -С. 13-16.

6. Денцель Е.С. Инженерная деятельность и ее роль в социуме // Молодежный научно-технический вестник. 2014. №7. С.40.

7. Леньков С.Л., Рубцова Н.Е. Это неуловимое понятие профессии // Институт психологии Российской Академии Наук. Организационная психология и психология труда. 2018. Т. 3. № 3. С. 9-38.

8. К Кононова Г.А., Циганов В.В. Профессиональная надежность персонала как фактор эффективной деятельности организации // Ученые записки Международного банковского института. 2017. №20. С.111-123.

9. Малащук Л.С., Маряшин Ю.Е., Филатов В.Н. К вопросу о функциональной надежности человека в экстремальных ситуациях // Проблемы безопасности полетов. 2012. №5. С.21-27.

10. Романова Е.С. 99 популярных профессий. Психологический анализ и профессиограммы. СПб.: Питер. 2008. 464 с.

11. Morosanova V. Regulatory and personality predictors of the reliability of professional actions / V.Morosanova, I.Gaidamashko, S.Chistyakova, N.Kondratyuk, A.Burmistrova-Sevenkova// Psychology in Russia: State of the Art. Volume 10.Issue 4. 2017.P. 195-207.

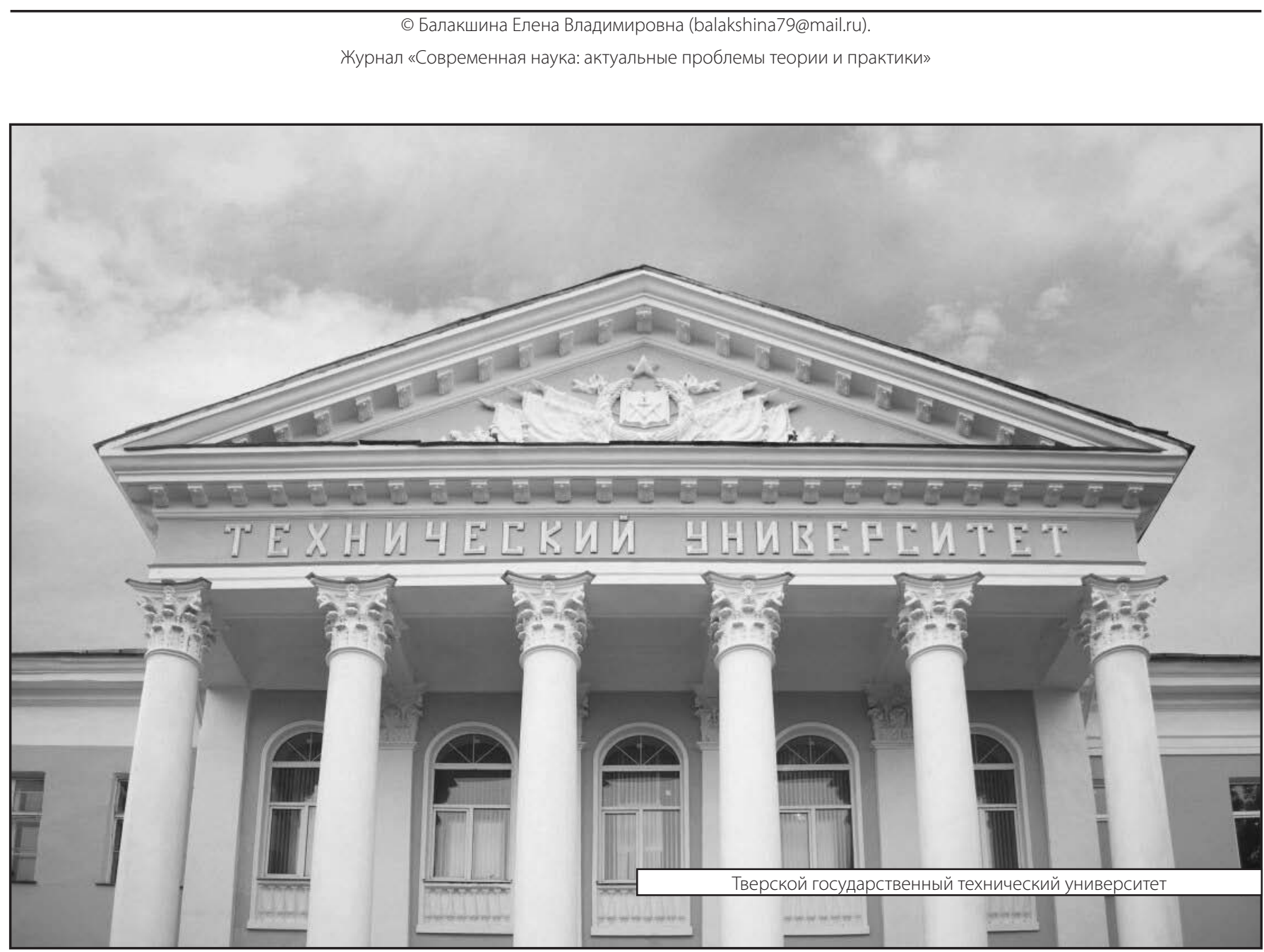

